\title{
Representasi Pewayangan Modern: Kajian Antropologi Sastra dalam Novel Rahvayana Aku Lala Padamu karya Sujiwo Tejo
}

Representation of Modern Puppet: Anthropological Studies of Literature in Novel Rahvayana Aku Lala Padamu by Sujiwo Tejo

Diki Febrianto $^{\mathrm{a}}$, Purwati Anggraini ${ }^{\mathrm{b}}$

${ }^{a b}$ FKIP, Universitas Muhammadiyah Malang

Pos-el: dikifebrianto45@gmail.com ${ }^{\mathrm{a}}$, poer1979ang@ gmail.com ${ }^{\mathrm{b}}$ doi.org/10.26499/jentera.v8i1.1192

\begin{abstract}
Abstrak: Penelitian ini berjudul "Representasi Pewayangan Modern: Kajian Antropologi Sastra dalam Novel Rahvayana Aku Lala Padamu karya Sujiwo Tejo". Pembahasan di dalam artikel ini dibatasi pada dua aspek, yaitu representasi pandangan dunia dan representasi unsur kebudayaan secara umum. Penelitian ini bertujuan untuk mengungkap kedua aspek, yang terdapat dalam novel Rahvayana Aku Lala Padamu karya Sujiwo Tejo. Pembahasan menggunakan metode deskriptif analitik dengan cara memaparkan suatu kenyataan disusul dengan analisis. Teori yang digunakan adalah teori representasi dengan pendekatan antropologi sastra. Sumber data penelitian ini adalah novel Rahvayana Aku Lala Padamu karya Sujiwo Tejo. Wujud data penelitian berupa kumpulan cerita yang mengandung unsur budaya yang mengalami perubahan. Hasil dari penelitian ini terdapat 1) Pandangan dunia: representasi pewayangan modern (struktur dialogis) dan kelompok sosial dalam novel Rahvayana Aku Lala Padamu karya Sujiwo Tejo. 2) unsur kebudayaan secara umum: sistem kemasyarakatan, sistem bahasa dan sastra, dan system pengetahuan.
\end{abstract}

Kata-kata kunci: representasi, modern, dan kebudayaan

Abstract: This research paper is entitled "Modern Puppet Representation: Anthropological Studies of Literature in Sujiwo Tejo's Rahvayana Aku Lala Novel". The discussion in this article paper is limited to two aspects, namely the representation of world views and representations of elements of culture in general. This study aims to uncover both aspects, which are found in Sujiwo Tejo's novel Rahvayana Aku Lala Padamu. The dDiscussion uses a descriptive-analytical methods by describing a reality followed by analysis. The theory used is representation theory with a literary anthropology approach. The source of this research data is the novel Rahvayana Aku Lala Padamu by Sujiwo Tejo. The form of research data is in the form of a collection of stories that contain cultural elements that experience change. The results of this study are 1) World view: representation of modern wayang (dialogical structure) and social groups in the novel Rahvayana Aku Lala Padamu by Sujiwo Tejo. 2) elements of culture in general: social systems, language and literary systems, and knowledge systems.

Keywords: representation, modern, and culture

How to Cite: Febrianto, Diki dan Purwanti Anggraini. (2019). Representasi Pewayangan Modern: Kajian Antropologi Sastra dalam Novel Rahvayana Aku Lala Padamu Karya Sujiwo Tejo. Jentera: Jurnal Kajian Sastra, 8 (1), 12-25. (Https:// doi.org/10.26499/jentera.v8i1.1192)

\section{PENDAHULUAN}

Sebagai seni pertunjukan tradisional, wayang adalah bagian dari budaya lokal Indonesia yang mengandung berbagai unsur kearifan budaya lokal di suatu daerah (Bahardur, 
2018). Pewayangan merupakan kebudayaan yang memiliki unsur kebudayaan di suatu wilayah yang biasanya berupa pertunjukan, kini hadir dengan bentuk kesusastraan dalam suatu karya sastra. Karya sastra merupakan representasi dari kehidupan melalui budaya yang dituangkan dalam bentuk kreativitas dan imajinasi pengarang melalui karyanya. Kejadian dalam suatu karya sastra dalam hal ini objeknya novel, merupakan kejadian yang faktual atau akan terjadi dalam kehidupan. Novel sebagai bagian dari bentuk sastra memiliki dan mengandung isi realita yang di dalamnya terdapat suatu kejadian atau peristiwa dan perilaku yang dialami dan dibuat manusia (tokoh). Kejadian yang terjadi di dalam kehidupan masyarakat, tidak lepas dari filsafat budaya yang berkembang di suatu wilayah, seperti novel sebagai suatu karya yang berisi cerita tentang kehidupan kebudayaan yang terjadi dalam realita kehidupan. Suatu pembelajaran dapat diambil dari sebuah novel sehingga dapat diambil manfaat dan pelajaran untuk pedoman hidup menjadi lebih baik lagi dan karya sastra kerap dipandang sebagai salah satu upaya merepresentasikan kejadian faktual, oleh sebab itu karya sastra dikatakan imitasi maupun peniruan dari kejadian faktual. Sastra menunjukan bayangan kehidupan, dan kehidupan merupakan keadaan sosial yang konkret (Saptawuryandari, 2015:195). Dari pernyataan tersebut meliputi hubungan kehidupan di masyarakat, individu, dan fenomena yang terjadi.

Sebagai perwakilan pada dasarnya representasi tidak berbeda dengan tanda, simbol dan lambang. Secara definitif berarti merupakan perwakilan dari sesuatu yang lain, sebagai pengganti objek faktual. Selanjutnya (Barker, 2009: 140) memaparkan bahwa representasi bukan mimesis, bukan penjiplakan atas kenyataan sesungguhnya, representasi adalah ekspresi estetis, sebuah rekonstruksi dari situasi yang pada kenyataanya. Representasi menghubungkan konsep dalam pikiran dengan menggunakan bahasa untuk mengartikan suatu objek yang berupa benda, orang, maupun kejadian nyata, dan imajinasi dari objek tersebut (Hall, 1995: 17). Representasi beranggapan bahwa, semua objek yang berupa orang, benda, maupun kejadian yang dikorelasikan dengan konsep yang terdapat di kepala atau pengetahuan yang telah ada. Tahap selanjutnya yaitu, dalam proses mengartikan memalui bahasa yang terdapat pada semua proses dari konstruksi arti.

Untuk mengungkap pembahasan representasi dalam penelitian ini, digunakan representasi pandangan dunia dan unsur kebudayaan secara umum yang terkandug dalam novel Rahvayana Aku Lala Padamu karya Sujiwo Tejo. Kejadian yang terjadi pada jiwa atau batin manusia, merupakan kejadian atau bahan sastra yang meliputi, hubungan sosial antara individu maupun masyarakat (Damono, 2002: 1). Oleh karena itu, sangat erat kaitanya dengan hubungan sastra dan budaya masyarakat. Seiring perkembangan zaman 
keberadaan wayang saat ini sudah mengalami penurunan minat, di kalangan generasi muda. Ditandai dengan rendahnya minat generasi muda untuk mempelajari dan melestarikan wayang. Novel Rahvayana Aku Lala Padamu, merupakan cerita pewayangan yang terdapat di dalam novel karya Sujiwo Tejo, menceritakan dan mengkombinasikan kisah pewayangan mengunakan analogi cerita sejarah sebagai bentuk pengetahuan pengarang yang di tuangkan ke dalam tulisanya. Dialog antar tokoh ditunjukan dengan interaksi yang berbeda. Di dalam bahasan setiap cerita dan dialog antar tokoh, berbeda dari cerita pewayangan, tetapi tetap dalam konteks cerita pewayangan.

Sebagai media dalam melestarikan kebudayaan Indonesia yang memiliki strata tertinggi, melestarikan wayang merupakan kewajiban untuk mempertahankan aset yang tidak dapat ditukar nilainya oleh apapun. Karena wayang mengandung falsafah dari kehidupan masyarakat Indonesia yang sangat berperan penting dalam merekam setiap perkembangan dan perjalanan kejadian kehidupan dari masa ke masa. Pewayangan melukiskan kutural bangsa Indonesia dengan mengimprovisasi dan mengkonstruksi budaya yang dapat diterima dengan mudah di masa ini. Salah satu bentuk melestarikan sekaligus upaya mempertahankan dan mengembangkan suatu kebudayaan dalam upaya menjaga eksistensi wayang.

Tujuan dari penelitian ini adalah mengidentifikasi unsur-unsur budaya pewayangan yang terdapat dalam novel Rahvayana Aku Lala Padamu karya Sujiwo Tejo . Proses awal dengan cara mengidentifikasi cerita pewayangan yang diwakili cerita modern melalui representasi pewayangan modern yang dianalisis struktur kebudayaan. Struktur kebudayaan dalam penelitian ini meliputi pandangan dunia, dialogis, menganalisis cerita pewayangan yang dianalogikan dengan cerita sejarah melalui unsur kebudayaan dengan sistem bahasa dan sastra, dan kebudayaan secara umum sebagai sistem pengetahuan dalam novel Rahvayana Aku Lala Padamu karya Sujiwo Tejo.

\section{LANDASAN TEORI}

Penelitian ini pada dasarnya mengungkap bahwa kebudayaan wayang sebagai representasi unsur budaya. Hal ini akibat dari pengaruh pandangan dunia pencipta karya sastra terhadap bentuk karya sastra, yaitu pewayangan yang terdapat pada novel Rahvayana Aku Lala Padamu. Hal ini akan menimbulkan relasi antara kebudayaan dan sastra sebagai objek yang dikaji. Sehingga akan digunakan pendekatan antropologi sastra dalam penelitian ini.

Menurut (Ratna, 2011: 31) antropologi sastra merupakan penyelidikan dan suatu proses karya sastra yang di dalamnya mengandung unsur kebudayaan yang universal. Pernyataan tersebut memiliki pemahaman dan sudut pandang yang luas. Karya sastra 
bukan suatu refleksi atau pemantulan dari kenyataan, tetapi pembelokan, sehingga dapat menimbulkan keragaman dari suatu kebudayaan yang berarti (Ratna, 2011: 31). Dalam relasi ini akan terjadi hubungan dari keduanya, antara sastra dan antropologi yang memiliki keseimbangan yang dinamis. Hubungan antara antropologi sastra dan kebudayaan, seimbang dengan hubungan antara kesusastraan dan kebudayaan. Dalam antropologi sastra, unsur antropologi atau kebudayaan bagian dari karya sastra sebagai acuan, sedangkan antropologi budaya memiliki kedudukan yang setara, karena kebudayaan adalah perkembangan dari antropologi itu sendiri.

Penelitian ini menggunakan teori representasi. Representasi merupakan suatu perihal sebagai perwakilan suatu keadaan (Sulistiyana, 2014). Dimaksud dalam penelitian ini adalah bentuk representasi pewayangan modern dalam karya sastra. Pada penelitian ini kebudayaan wayang modern yang mewakili padangan dunia dan unsur kebudayaan secara umum. Representasi menghubungkan konsep dalam pikiran dengan menggunakan bahasa untuk mengartikan suatu objek yang berupa benda, orang, maupun kejadian nyata, dan imajinasi dari objek tersebut (Hall, 1995). Representasi beranggapan bahwa, semua objek yang berupa orang, benda, maupun kejadian yang dikorelasikan dengan konsep yang terdapat di kepala atau pengetahuan yang telah ada. Tahap selanjutnya yaitu, dalam proses mengartikan memalui bahasa yang terdapat pada semua proses dari konstruksi arti. Oleh karena itu, pendekatan yang digunakan dalam penelitian ini adalah pendekatan antropologi sastra sebagai pandangan dari konsep yang pertama, sastra sebagai konsep yang kedua dari teori representasi yang dipaparkan di atas.

\section{METODE PENELITIAN}

Metode yang digunakan dalam penelitian ini adalah deskriptif analitik dengan cara memaparkan suatu kenyataan disusul dengan analisis. Penelitian ini mengunakan pendekatan antropologi sastra dengan menggunakan teori representasi. Dimaksud dalam penelitian ini adalah bentuk representasi pewayangan modern dalam karya sastra. Pada penelitian ini kebudayaan wayang modern yang mewakili padangan dunia dan unsur kebudayaan secara umum.

Langkah kerja dalam penelitian ini yaitu dengan (1) menentukan objek yang akan diteliti yaitu novel Rahvayana Aku Lala Padamu karya Sujiwo Tejo, sebagai objek yang diteliti; (2) membaca novel dan sumber-sumber referensi sebagai acuan dari penelitian yang berupa buku tentang penelitian sastra, antropologi sastra dan jurnal; (3) menentukan pendekatan yang sesuai dengan isi novel, menganalisis isi novel dengan mengklasifikasikan sesuai dengan pendekatan yang ditentukan, wujud data penelitian 
berupa kumpulan cerita yang mengandung unsur budaya yang mengalami perubahan. Dalam teknik pengumpulan data, ojek penelitian yang berupa novel dibaca berulang-ulang dan mengklasifikasikan data.

\section{HASIL DAN PEMBAHASAN}

Unsur kebudayaan merupakan bagian dari suatu kebudayaan yang dapat digunakan sebagai analisis. Menurut (Koentjaraningrat, 2015: 156) kebudayaan terbagi ke dalam tujuh unsur, yakni bahasa, sistem pengetahuan, organisasi sosial, sistem peralatan hidup dan teknologi, sistem mata pencaharian hidup, sistem religi, dan kesenian. Dalam penelitian yang berjudul Representasi Pewayangan Modern pada novel Rahvayana Aku Lala Padamu karya Sujiwo Tejo terdiri atas dua hal yaitu, 1) Pandangan dunia: representasi pewayangan modern (struktur dialogis) dan kelompok sosial dalam novel Rahvayana Aku Lala Padamu karya Sujiwo Tejo. 2) unsur kebudayaan secara umum: sistem kemasyarakatan, sistem bahasa dan sastra, dan sistem pengetahuan.

\section{Pandangan Dunia}

Pandangan dunia merupakan sebagian konsep pandangan hidup yang dimiliki seseorang atau golongan masyarakat yang bertujuan untuk menanggapi dan menerangkan suatu masalah yang terdapat di dunia. Pandangan dunia adalah bentuk ekspresi pada suatu golongan sosial pada saat karya sastra diciptakan. Pandangan dunia akan terungkap melalui tokoh, yang terdapat di dalam cerita. Pandangan dunia melalui tokoh yang ditampilkan pengarang merupakan struktur keseluruhan yang bermakna. (Kadir, 2013: 131) menyatakan bahwa, pandangan dunia pencipta tidak hanya mengungkapkan individu, tetapi adalah pengungkapan kelompok bersama atau kelompok masyarakat suatu wilayah tertentu.

Karya sastra merupakan bagian struktur yang memiliki arti dan sebagai hasil perbuatan dunia pencipta dan bukan individu, tapi anggota masyarakat (Endaswara, 2003: 57). Pandangan dunia dalam sastra dianggap sama dengan cara pandang dan sudut pandang. Dalam kaitanya, sastra disejajarkan dengan pesan, tema, dan amanat. Pandangan dunia di sini dapat diartikan bahwa pandangan dunia merupakan tujuan secara luas tentang dunia itu sendiri, ekspresi jiwa melalui bahasa dan bernalar subjek kolektif dengan lingkungan sosial yang terjadi dalam periode sejarah lama dan panjang.

Goldmann (Ratna, 2011), pandangan dunia adalah pandangan secara umum terkait dunia, pengungkapan jiwa dengan perantara dialektis masyarakat luas dengan wilayah sosial, yang terjadi pada waktu yang panjang. Dalam sastra pandangan dunia mendapatkan kedudukan sebagai intensitas hubungan manusia dengan keadaan ling- 
kunganya, bagaimana manusia dengan lingkunganya begitu dengan lingkungan terhadap manusianya. Perkembangan ide yang konteknya meliputi sejarah, dinilai dari masa ke masa, karena setiap masa maupun periode akan memiliki perbedaan. Oleh karena itu, pada penelitian ini terdapat perbedaan yang mencolok tepatnya pada cerita pewayangan saat ini dengan pewayangan dahulu.

"Aku pun merasa relaks, Sinta. Aku merasa bisa mengutarakan banyak hal. Padahal, itu baru perkenalan sekaligus pertemuan pertama. Kita tak telepon-teleponan lebih dulu. Tak SMS-an, BBM-an, dan email-email-an lebih dulu. Tak ada. Tahu-tahu ketemu. Tahu-tahu kenalan. Tahu-tahu aku sudah relaks ngobrol panjang lebar denganmu yang sudah berganti baju tanpa bra. Ya, tanpa bra. Betul kan Sinta? Aku lihat jelas kok, sembulan puting susumu pada T-shirt-mu.... Heuheuheu...” (Tejo, 2018: 13).

Menandai bahwa perkembangan teknologi ditandai dengan inovasi-inovasi yang berkembang, alat komunikasi yang canggih, dan media komunikasi yang beragam. Kutipan di atas sebagai bukti, bahwa pada novel Rahvayana Aku Lala Padamu karya Sujiwo Tejo, sebagai bentuk perwakilan pewayangan tradisional dikemas dengan modern. Interaksi yang komunikatif ditunjukan dengan setiap adegan cerita di dalam novel. Dengan menggunakan alat komunikasi dan benda yang menunjuk keapad $T$-shirt yang berada pada era modern ini, lebih menjadikan suatu pewayangan hidup di zaman ini juga, dan dapat menjadikan masyarakat milenial menjadi mudah melestarikan kebudayaan pewayangan.

"Sebenarnya, Sinta, waktu dari Ngurah Rai Bali sampai bandara Changi Singapura itu aku balik kanan tak jadi menyertaimu ke Berlin, semua, ya, gara-gara Lawwamah, Mutmainah, Supiah, dan Amarah. Di Louge itu aku bohong kepadamu. Aku bohong kepadamu bahwa aku lupa janji sama orang, bahwa aku harus bergegas ke Pulau Moyo, sebelah utara Sumbawa, ketemu John Lennon." (Tejo, 2018: 15).

Pandangan dunia diungkapkan dengan kondisi pewayangan yang terkesan hidup dimasa sekarang, dengan cerita berkunjung ke berbagai Negara dan melakukan perjalanan layaknya orang yang sedang berlibur, adalah salah satu bukti yang ditunjukan bahwa adanya pandangan dunia dibuktikan sebagai angkatan saat ini.

\subsection{Representasi Pewayangan Modern (Struktur Dialogis) yang Terdapat dalam Novel Rahvayana Aku Lala Padamu karya Sujiwo Tejo}

Dikaitkan dengan peran subjek kolektif, novel Rahvayana Aku Lala Padamu menceritakan pewayangan hasil dari improvisasi dan konstruksi kisah pewayangan. Untuk melukiskan gejala kultural dengan memanfaatkan cara-cara konstruktif karena pengaruh perubahan tradisi sekarang. Memberi kesan cerita rekonstruksi dengan pewayangan versi asli, tetapi sebagai hasil konstruksi dan arketipe. Citra arketipe dan solidaritas primordial, ditunjukan dengan kejadian-kejadian dalam novel, dialog sederhana antar tokoh, analogi cerita seperti Rama Sinta dan Trista and Isolde. Di dalam dialog 
membahas cerita di luar aspek cerita pewayangan, argumentasi terjadi ketika keduanya membahas suatu topik dalam dialog. Dipengaruhi oleh penggunaan bahasa modern adalah salah satu pramodial dari novel Rahvayana Aku Lala Padamu yang merupakan hasil dari seorang penulis, dengan penggabungan cerita pewayangan dengan cerita yang ada pada masa kini, hal ini salah satu bentuk dari kreatifitas seorang penulis Sujiwo Tejo. Memiliki banyak pengalaman dalam membaca cerita, selanjutnya implementasi tertuang dalam karyanya yang berupa novel.

Cerita pewayangan yang sebenarnya memiliki kesamaan dengan apa yang dijelaskan di atas. Dalam kutipan cerita dalam buku R.K. Narayan yang berjdul Ramayana Mahabarata, awal Rama bertemu dengan Sinta, dengan mengamati Sinta ketika sedang bermain dengan sahabat-sahabatnya di atas sebuah balkon. Rama takjub melihat kecantikan Sinta, pada waktu yang sama Sinta memerhatikan Rama. Pelan-pelan Sinta berhenti mengamati Rama lewat sampai tidak terlihat lagi. Pikiran Sinta bingung, karena tatapan rama telah berbicara pasal cinta dan cinta itu mulai menyebar dalam diri Sinta sampai dirinya menjadi tidak enak badan. Dalam penggalan cerita di atas menunjukan bahwa dalam cerita pewayangan yang sebenarnya menunjukan interaksi komunikatif dengan batin yang kuat, ditunjukan ketika Rama mengikuti sayembara untuk memperebutkan Sinta. Dengan tujuan yang jelas yaitu untuk mendapatkan Sinta, tatapan Rama yang kagum akan Sinta dapat Sinta terima dengan perasaanya ketika membalas tatapan Rama. Dengan kondisi Sinta jatuh cinta kepadanya.

Dalam novel Rahvayana Aku Lala Padamu, yang menceritakan kisah Rama dan Sinta, terdapat komunikasi yang komunikatif, perbedaan terdapat pada alur cerita yang sama dengan cerita yang mengalami konstruksi.

"Siapa membuang bayi melek tanpa tangisan begini? Ckckck .... Teganya! Teganya! Rambut lebat berlumur lumpur. Ckckck .... Pipinya tembam. Dadanya montok. Ckckck .... Matanya hidup tanpa tangisan. Teganya! Teganya! Lya. Iya. Teganya! Siapa tega membuang bayi sepi sendiri sampai sore begini. Kelaminya perempuan. Ckckck .... Ayo kita bersihkan. Taruhan nanti kulitnya kuning lansat bagai kelopak padma. Ckckck .... Itu jari-jarinya, duh, seperti pisang susu. Perutnya endut-endutan. Wajahnya damai tanpa tangisan..... Teganya! Teganya!” (Tejo, 2018: 6).

Awal pertemuan Rama terhadap Sinta ditunjukan dengan sikap yang kurang pantas dilakukan oleh putra seorang raja. Rasa kagumnya terlihat ketika Rama berulangulang mengatakan "Teganya! Teganya!” karena melihat Sinta dengan segala kelebihan yang ia miliki sedang sendirian. Tiga kali Rama mengungkapkan kekagumanya dengan menjelaskan tiga kelebihan yang Sinta miliki. Dalam Rama mengungkapkan kecantikan tersebut tidak lain itu sebagai nilai estetis yang diceritakan secara tidak langsung. Kutipan di atas menujukan citra arketipe, karena bentuk cerita tersebut berdasarkan cerita pe- 
wayangan yang sesungguhnya, tapi dalam bentuk yang telah dikembangkan dan menjadi sesuatu yang baru. Awal pertemuan ini menunjukan interaksi yang komunikatif tapi dengan versi yang lain, dengan pengalaman yang pencipta miliki.

\subsection{Kelompok Sosial}

Kelompok sosial adalah salah satu aspek yang menjadi unsur kebudayaan dalam analisis pandangan dunia. Kaitanya dengan karya seni yang sama dengan karya sastra. Karya seni adalah akibat dari interaksi antarvariabel atau dapat dikatakan bahwa karya seni tidak berdiri sendiri, tidak menawarkan wajah yang sama, baik pada kreativitas seorang penulis baik pada pembaca dalam proses membaca. Pewayangan menjadi objek penelitian di sini menduduki karya seni. Kaitanya dengan karya sastra keduanya memiliki persamaan, dan di dalamnya mengandung struktur sosial yang menyangkut sistem perkataan, tingkah laku, isyarat, pikiran dan perasaan.

"Nuwun inggih sendika dhawuh" dengan tunduk dan menghaturkan sungkem di depan ramandanya, begitulah Raden Rama bertutur pada Ramanda Prabu. Mendengar kabar sayembara "menthang langkap" di Negara Manthilidirja untuk memperebutkan Dewi Sinta yang terkenal cantik jelita. Doa restu dari Ramanda Prabu yang diharapkan Raden Rama agar dapat memenangkan sayembara itu, seraya menghaturkan sembah bekti di hadapan Ramandanya (Susetya, 2008: 15). Sebagian kutipan cerita Ramayana, menunjukan ketaatan seorang putra terhadap orang tuanya, dengan perkataan yang lembut, sopan dan tegas. Tingkah laku yang adab terhadap orang yang lebih tua, ditunjukan ketika Rama sungkem dihadapan Ramandanya, sebagai anak yang menghormati dan melaksanakan perintah orang tuanya, Rama melakukan kewajibanya atas perintah Ramandanya untuk mengikuti sayembara memperebutkan seorang gadis yang cantik jelita. Demi berlangsungnya tahta Ayodya. Dalam novel Rahvayana Aku Lala Padamu memberikan cara sekaligus gambaran yang baru terhadap cerita pewayangan yang sebenarnya. Hal ini dapat dilihat dalam kutipan berikut.

"Hai Sinta, apa kabar? Sudah dua-tiga bulanan tak terasa kita pisahan sejak teratai warna pink itu... Bali... Bangau-bangau itu... Kicau jalak Bali... Tari Legong Keraton..... Rasanya juga kemarin sore kita makan ... apa itu ... yang di Sry`s Warung di Ubud itu, lho.... Seingatku pelayanannya bilang pandan-wrapped chicken with sesame reriyaki dipping sauce.... Betul? Entahlah. Aku suka semacam daun seledrinya. Kamu bilang daun itu dari Italia. Pedas-pedas wangi gimana, gitu. Hmmm....” (Tejo, 2018: $11)$.

Sikap sosial yang ditunjukan Rama dalam dialog sederhana terhadap Sinta, menyapa dengan sikap kepedulian seorang Rama terhadap orang yang ia cintai dalam cerita pewayangan sesungguhnya. Dengan bercerita, adalah salah satu strategi Rama dalam kutipan di atas, agar selalu bersama Sinta dan salah satu bentuk pengetahuan yang 
pengarang miliki, lalu ia tuangkan pada karyanya. Melalui pengalaman membaca cerita di luar pewayangan yang luas dan banyak, menjadikan cerita pewayangan di atas memiliki cerita yang beranekaragam dengan ditunjukan melalui beberapa dialog yang menceritakan cerita di luar konteks cerita pewayangan. Tingkah laku seorang Rama dapat dilihat dalam penggalan cerita.

"Siapa membuang bayi melek tanpa tangisan begini? Ckckck .... Teganya! Teganya! Ckckck .... Itu jari-jarinya, duh, seperti pisang susu. Perutnya endut-endutan. Wajahnya damai tanpa tangisan ......” Teganya! Teganya! (Tejo, 2018: 6).

Menujukan tingkah laku seorang anak raja dalam pewayangan modern, berbeda dengan pewayangan yang sesungguhnya. Ketika seorang anak raja melihat seorang putri, dengan memandangi saja cukup untuk mengaguminya, berbeda dengan penggal cerita di atas terlihat Rama yang selalu tertawa lepas ketika melihat kecantikan Sinta. Dalam hal ini tidak sesuai dengan kenyataan yang sebenarnya.

\section{Unsur Kebudayaan Secara Umum}

Konteks kebudayaan sendiri merupakan sesuatu hal yang mencangkup sangat luas. Suatu karya dapat tergolongkan dalam kebudayaan. Hal ini kaitanya dengan kebudayaan tidak ada batasan yang jelas mengenai ilmu-ilmu yang ada pada saat ini karena semua ilmu akan menjadi suatu budaya. Untuk itu, agar menghindari kesalah pahaman tentang budaya, cara yang dapat dilakukan yaitu dengan memberikan pengertian yang jelas terhadap setiap bidang ilmu. Unsur kebudayaan secara umum pada novel Rahvayana Aku Lala Padamu, memiliki genre aliran cerita yang beragam yang mencangkup cerita nabi Musa perwakilan dari genre religi, cerita Trista and Isolde perwakilan dari cerita percintaan genre romantis.

\subsection{Sistem Kemasyarakatan}

Kemasyarakatan merupakan salah satu aspek dalam kebudayaan yang paling luas. Masyarakat dan kebudayaan sulit untuk dipisahkan. Perbedaan dari keduanya dapat dibedakan melalui intensitas atau keadaaan, sudut pandang, dan cara lain yang dilakukan pada saat terjadinya proses pemahaman. Sistem kebudayaan hampir sama dengan sistem kemasyarakatan. Tetapi dalam hubungan ini sistem kemasyarakatan dibatasi dalam bentuk kekerabatan yang meliputi sistem komunikasi dari sekumpulan manusia yang paling kecil hingga yang paling besar dari sebagian masyarakat. Dipandang dari sudut sosiologis, karya sastra yang baik yaitu karya sastra yang mampu mewakili, merepresentasi masyarakat di suatu tempat. Dengan menikmati atau mempelajari suatu karya sastra, sama halnya dengan merasakan peristiwa-peristiwa yang berkaitan dengan masyarakat di wilayah tersebut. Selektivitas dan kreativitas dilakukan dengan mencapai tujuan estetis, 
sedangkan isinya tetap. Karya yang baik adalah karya yang melukiskan aspek kebudayaan yang relatif sama tapi dilakukan dengan mempertimbangkan relevansi dari mutu estetisnya. Seperti pada novel Rahvayana Aku Lala Padamu terletak dalam penggalan cerita sebagai berikut.

"Menurut mbak-mbak cerdas berkacamata ini, yang barusan ditayangkan televisinya adalah musikal "Ramayana". Ada bros teratai warna pink, memang, tapi dikenakan di antara belah dada. Itu belah dada Dewi Sukesi. Saat itu putri Prabu Sumali Raja Alengka ini sedang diwejang Sastrajendra Hayuningrat Pangruating Diyu oleh Resi Wis Rawa. ini sastra, tepatnya mantra, mantra ilahiah sebagai syarat Sukesi mau dipersunting lakilaki." (Tejo, 2018: 25).

Keadaan estetis terlihat dari dalam penggalan cerita di atas terlihat pada pengetahuan cerdas yang dimiliki mbak-mbak yang berkacamata. Pertimbangan dengan relevansi cerita pewayangan yang sebenarnya terlihat pada topik yang dibahas, yaitu pasal musikal "Ramayana" dengan cerita Dewi Sukesi yang pada saat itu Prabu Sumali sebagai raja Alengka sedang diwejang Sastrajendra Hayuningrat Pangruating Diyu oleh Resi Wis Rawa. Dalam faktanya raja Alengka dipimpin oleh Prabu Dasarata, kaitanya dengan penelitian ini Prabu Sumali merupakan gambaran dari Prabu Dasarata menurut pencipta, dengan kualifikasi yang pengarang tentukan agar mewakili peran seorang raja.

Perwakilan dari cerita pewayangan yang sebenarya ditunjukan dalam sistem kekerabatan ketika Raden Rama Wijaya beserta Raden Laksmana memakai pakaian prajurit dan segerah bertolak ke Negara Manthilidirja. Ketika hendak keluar dari istana, perjalanan kedua putra raja Ayodya disambut dan dielu-elukan oleh para wiratama dan prajurit serta para kawuladasih, seolah-olah mereka mengantarkan seorang pahlawan ke medan peperangan dengan melemparkan bunga-bunga sebagai penghormatan kepada pangeran. Semua prajurit mengangantarkanya pangeran sampai perbatasan Negara Ayodya.

Kekerabatan sosial dapat dilihat antara putra raja dengan prajuruit kerajaan Ayodya. Dengan kata lain kekerabatan sosial dalam lingkup kecil yaitu keluarga, konteks di sini pada kerajaan, sama halnya keluarga. Rasa simpati seorang prajurit terhadap atasan dilakukan untuk member kepedulian dan semangat agar nantinya dapat memenangkan sayembara untuk merebutkan Putri Sinta. Kekerabatan pada novel Rahvayana Aku Lala Padamu tampak pada hubungan antara Rama dan Sinta dalam masa pendekatan, dengan penuh perjuangan yang berupa negosiasi dalam dialog dengan cara rama bercerita di dalam setiap dialog.

\subsection{Sistem Bahasa dan Sastra}


Pada bagian analisis bahasa dan sastra dalam novel Rahvayana Aku Lala Padamu diberikan makna khusus dalam satu subjudul, hal ini akan memberi pemahaman yang memadai terhadap suatu kebudayaan baik dalam bentuk lisan maupun tertulis. Sebagai sistem sastra, karya seni dapat dimasukan kedalam sistem bahasa, dengan pertimbangan pertama seni bahasa adalah seni sastra, kedua aspek keindahan karya sastra bukan keindahan yang dinikmati secara visual dan audio, dengan demikian dapat dinikmati dalam bentuk wacana yang berupa teks dan kemampuan bahasa secara keseluruhan untuk mengungkap makna tersembunyi yang diciptakan pengarang melaui kayanya, ketiga keindahan karya sastra tertunda dari kalimat demi kaliamat, keempat karya sastra menceritakan sesuatu sedangkan karya seni menunjukan sesuatu.

Dari kedua aspek, yaitu sistem bahasa dan sastra dalam hal ini tidak dapat dipisahkan. Di pandang dari sisi bahasa, karya sastra dapat diartikan model kedua bahasa yang diaplikasikan. Bahasa tanpa sastra hanya menunjukan suatu kata dan kalimat sebagai kode atau sesuatu yang terkesan akan sebuah aturan. Dengan bahasa proses komunikas akan terjadi dalam kehidupan sehari-hari karena sengaja dilakukan, sedangkan bahasa sastra adalah pemanfaatan komunikasi yang sengaja dilakukan dengan memenuhi aspek estetis.

Bahasa dan sastra kaitanya dengan antropologi sastra, dalam hal ini antropologi mempermasalahkan hubungan antara manusia dengan bahasa, dengan sastranya. Dalam novel Rahvayana Aku Lala Padamu adalah salah satu bentuk bahasa yang mengandung nilai sastra, tampak dapat dilihat dalam setiap alur cerita dalam novel.

"Oh, ya, bagaimana Berlin, Sinta? Jadi kamu nonton opera "Tristan and Isolde?" Hmmm... "Tristan and Isolde" ... Seorang kesatria dan seorang putri. Tristan berhasil memenangi sayembara memboyong Putri Isolde dari Irlandia. Tristan adu kesaktian melawan peserta sayembara lain bukan untuk diri pribadinya. Dia muncul di ajang perebutan putri itu atas perintah Raja Marke, pamanya. Isolde akan dijadikan pemasuri sang Raja. Tapi, di tengah jalan ketika hendak memboyong Isolde pulang, eh, Tristan jatuh hati. Isolde pun jatuh hati." (Tejo, 2018: 11).

Unsur cerita sastra di dalamnya dapat dilihat pada data di atas. Keindahan dalam novel dapat dinikmati pada setiap penggalan cerita. Secara konkret penggalan cerita dalam novel Rahvayana Aku Lala Padamu karya Sujiwo Tejo, memberi kesan yang berbeda dari cerita pewayangan biasanya. Data di atas menunjukan interaksi antara Rama dan Sinta, Rama bercerita pasal cerita Tristan and Isolde. Hal tersebut menunjukan seni bahasa yang digambarkan pengarang dengan mengandung nilai seni di dalamnya terdapat pada cerita Tristan and Isolde. Tristan and Isolde di dalam cerita melalui dialog di atas, sebenarnya antara cerita pewayangan tentang Rama dan Sinta memiliki kesamaan dengan Tristan and Isolde, menceritakan kisah percintaan, keduanya membahas tentang 
percintaan kedua anak bangsawan dari suatu kerajaan. Fenomena seperti ini, sebagai karya sastra dapat dinikmati dengan bentuk wacana, dari wacana tersebut dapat diungkap nilai estetisnya, yang makna yang tersenbunyi tesembunyi karena memang disembunyikan atau tidak oleh penciptanya. Data yang sama menunjukan pada cerita pada masa Tiongkok Kuno yang terdapat pada novel Rahvayana Aku Lala Padamu.

"Baginda Sri Ratu segerah teringat ungkapan orang-orang Tiongkok Kuno bahwa cantik itu kutukan. Itu baru cantik saja lho. Belum cantik dengan suara yang menggoyah iman siapapun pendengarnya, batin Sri Ratu." (Tejo, 2018: 8).

Di dalam setiap dialog Rama selalu bercerita kepada Sinta, topik pembahasanya di luar kontek pewayangan. Menceritakan kecantikan orang-orang Tiongkok, menjadi topik yang lumrah dalam sudut pandang ini karena dari awal cerita novel selalu bercerita. Hal ini seni pewayangan menunjukan sesuatu yang sengaja disembunyikan melalui karya sastra yang menceritakan sesuatu. Kecantikan dalam kontek kutipan diatas menunjukan kecantikan yang menjadi ciri utama dari sosok Sinta yang diluapkan Rama. Analogi kecantikan disamakan seperti Sri Ratu, pada kenyataanya tahta seorang ratu menepati kedudukan yang paling atas, Pandangan Rama terhadap Sinta mengibaratkan seorang ratu.

\subsection{Sistem Pengetahuan}

Sistem pengetahuan sangat bertentang dengan sistem sastra, ilmu pengetahuan adalah objektivitas dari pengetahuan, sedangkan karya sastra dapat diartikan subjektivitas imajinasi, sehingga dari kedua sistem tersebut tidak dapat dipertemukan. Sebagai interdisiplin, untuk menelaah keduanya, ada cara yang dapat dilakukanya yaitu pertama pengetahuan sebagai muatan, menceritakan unsur di antara unsur lainya, kedua menganggap karya sastra bukan imajinasi, melainkan suatu petunjuk suatu karya sastra juga merupakan ilmu pengetahuan. Hal ini diharapkan dapat menyetarakan perkembangan dari kedua sistem tersebut. Perkembangan melalui fenomena perkembangan dari masa ke masa mengacu pada analogi suatu cerita pewayangan pada abad ke-5 dengan pewayangn modern yang terdapat pada novel Rahvayana Aku Lala Padamu karya Sujiwo Tejo.

"Sebenarnya, Sinta, Waktu itu aku ingin menggambarkan paradok kepadamu melalui Black Swan yang mengantar Natalie Portman Memenangi Oscar sebagai Nina. Black Swan bersandar pada "Swan Lake", musik sepanjang masa yang digubah raksasa komposer Rusia, Tchaikovsky (Hmmm ... akankah suatu hari kita bisa mengunjungi makamnya ...). ”(Tejo, 2018: 28).

Data di atas menunjukan bahwa pada isi novel yang diteliti, cerita mengalami improvisasi dalam ceritanya. Dengan jelas bisa dikatakan bahwa pada masa pewayangan Rama dan Sinta masih belum mengenal cerita tentang Black Swan dan bertolak belakang dengan cerita dalam novel yang terbukti dalam penggalan di atas. Hal ini adalah salah sa- 
tu bentuk ragam pembahasan dari pengetahuan pengarang terhadap karyanya dengan mengkombinasikan cerita pewayangan dengan cerita di luar cerita pewayangan, dan kondisi atau fenomena seperti itu bukan bentuk imajinasi melainkan kreatifitas pengarang dengan imajinasi bahwa pantas untuk menggabungkan kedua unsur cerita dapat menjadi salah satu karya sastra sebagai perwakilan kebudayaan.

\section{SIMPULAN}

Dalam menciptakan sebuah karya, khususnya karya sastra dalam pembahasan pada penelitian ini terungkap bahwa, pengarang secara tidak langsung dapat mengangkat pembahasan di dalam karyanya dengan melihat dunia dan unsur budaya. Pada penelitian ini, pandangan dunia ditandai dengan berkembangnya teknologi yang berinovasi dan berkembang, alat komunikasi yang canggih, dan media komunikasi yang beragam. Suatu bentuk representasikan pengarang melalui cerita pewayangan. Pada pandangan dunia terbagi atas struktur dialogis dan kelompok sosial. struktur dialogis ditunjukan dengan komunikasi yang komunikatif antara Rama dan Sinta. Kelompok sosial yang ditunjukan pada tingkah laku tokoh dalam cerita.

Selanjutnya terdapat unsur kebudayaan secara umum yang meliputi sistem kemasyarakatan, yang terlihat pada penggalan cerita yang memiliki keadaan estetis. Sistem bahasa dan sastra, terlihat melalui interaksi antara Rama dan Sinta yang bercerita tentang Tristan dan Isolde. Sistem pengetahuan, diungkap ketika Rama dan Sinta bercerita tentang Black Swan, sebenarnya pada masa pewayangan belum ada cerita tersebut, hal ini merupakan bentuk improvisasi dan konstruksi pengarang terhadap karyanya.

\section{DAFTAR PUSTAKA}

Bahardur, I. (2018). Kearifan Lokal Budaya Minangkabau dalam Seni Pertunjukan Tradisional Randai. Jentera: Jurnal Kajian Sastra, 7 (2), 146.

Barker, C. (2009). Cultural Studies: Teori dan Praktik. Bantul: Kreasi Wacana.

Damono, S. D. (2002). Pedoman Penelitian Sosiologi Sastra. Jakarta: Pusat Bahasa, Departemen Pendidikan Nasional.

Endaswara, S. (2003). Pengantar Sosiologi Sastra. Yogyakarta: Pustaka Pelajar.

Hall, S. (1995). Representation: Cultural Representation and Signifying Practices. London: Sage Publications.

Kadir, H. (2013). Ekspresi Pandangan Dunia Kelompok Sosial Pengarang dalam Novel Laskar Pelangi Karya Andrea Hirata. Litera: Jurnal Penelitian Bahasa, Sastra, dan Pengajaranya, 12(1), 131.

Koentjaraningrat. (2015). Pengantar Ilmu Antropologi. Jakarta: PT. Rineka Cipta.

Ratna, N. K. (2011). Antropologi Sastra. Yogyakarta: Pustaka Pelajar.

Saptawuryandari, N. (2015). Pandangan Dunia Mochtar Lubis dalam Novel Senja di Jakarta. Aksara, 27 (2), 195-206.

Sulistiyana, P. (2014). Representasi Kemiskinan dalam Novel Jatisaba Karya Ramayda Akmal (Kajian Sosiologi Sastra). Bahtera Sastra: Antologi Bahasa dan Sastra Indonesia, 2. 
Susetya, W. (2008). Ramayana. Jakarta: PT. Buku Kita.

Tejo, S. (2018). Rahvayana Aku Lala Padamu. Yogyakarta: Penerbit Bintang. 